\title{
Erratum to: Sex Pheromone of the Pine False Webworm Acantholyda erythrocephala
}

\author{
Joseph K. Staples • Robert J. Bartelt • Allard A. Cossé • \\ Douglas W. Whitman
}

Published online: 14 February 2010

(C) Springer Science+Business Media, LLC 2010

Erratum to: J Chem Ecol (2009) 35:1448-1460

DOI 10.1007/s10886-009-9736-z

The presentation of Fig. 7 in the original version of this article contained a mistake. It is now corrected here.

The online version of the original article can be found at http://dx.doi. org/10.1007/s10886-009-9736-z.

J. K. Staples $(\bowtie)$

Department of Environmental Science,

University of Southern Maine,

37 College Avenue,

Gorham, ME 04038, USA

e-mail: jstaples@usm.maine.edu

R. J. Bartelt · A. A. Cossé

Crop Bioprotection Research Unit, USDA,

ARS National Center for Agricultural Utilization Research,

Peoria, IL 61604, USA

D. W. Whitman

School of Biological Sciences, Illinois State University,

Box 4120, Normal, IL 61790, USA

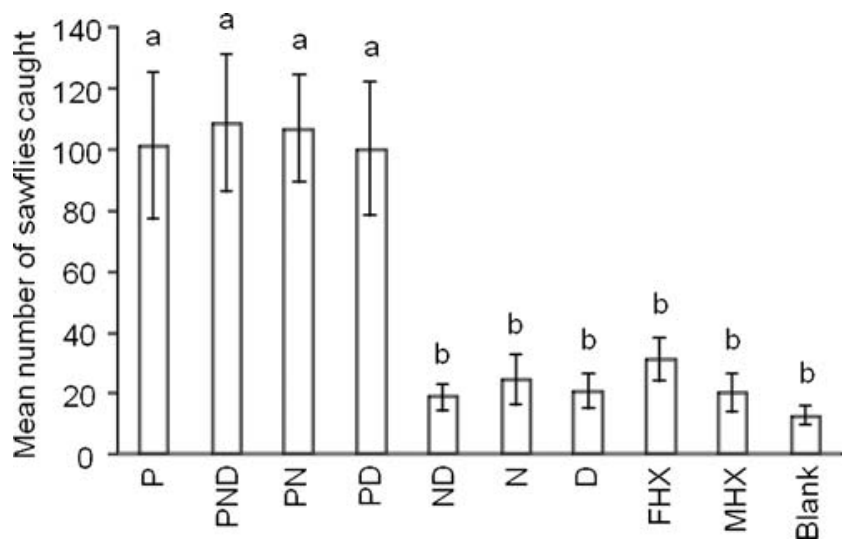

Fig. 7 Illinois field experiment 2002. Results show the mean number of male Acantholyda erythrocephala collected per treatment from April 17 through April 20. Error bars $=$ standard error of untransformed data. Different letters indicate significant differences at $P<0.05$ (ANOVA followed by Tukey HSD test). Treatments include $\mathrm{P}=(Z)$ 6,14-pentdecadienal $(50 \mu \mathrm{g}), \mathrm{N}=$ nonanal $(1 \mathrm{mg}), \mathrm{D}=$ decanal $(1 \mathrm{mg})$, $\mathrm{ND}=$ nonanal and decanal $(1 \mathrm{mg}$ each $), \mathrm{FHX}=$ female whole body washes (in hexane), MHX=male whole body washes (in hexane), and blank traps 